in vivo $35: 1611-1615(2021)$

doi:10.21873/invivo.12418

\title{
Impact of K-Ras Over-expression in Laryngeal Squamous Cell Carcinoma
}

\author{
VASILEIOS PAPANIKOLAOU ${ }^{1}$, ARISTEIDIS CHRYSOVERGIS ${ }^{1}$, STYLIANOS MASTRONIKOLIS ${ }^{2}$, \\ EVANGELOS TSIAMBAS ${ }^{3}$, VASILEIOS RAGOS ${ }^{4}$, DIMITRIOS PESCHOS ${ }^{5}$, DESPOINA SPYROPOULOU ${ }^{6}$, \\ PAVLOS PANTOS ${ }^{1}$, ATHANASIOS NIOTIS ${ }^{7}$, NICHOLAS MASTRONIKOLIS ${ }^{8}$ and EFTHYMIOS KYRODIMOS ${ }^{1}$ \\ ${ }^{1} 1^{\text {st }}$ ENT Department, Hippocration Hospital, University of Athens, Athens, Greece; \\ ${ }^{2}$ Medical School, University of Heraklion, Heraklion, Greece; \\ ${ }^{3}$ Department of Cytology, 417 VA Hospital (NIMTS), Athens, Greece; \\ ${ }^{4}$ Department of Maxillofacial Surgery, Medical School, University of Ioannina, Ioannina, Greece; \\ ${ }^{5}$ Department of Physiology, Medical School, University of Ioannina, Ioannina, Greece; \\ ${ }^{6}$ Department of Radiation Oncology, Medical School, University of Patras, Patras, Greece; \\ ${ }^{7}$ Department of Surgery, 417 VA Hospital (NIMTS), Athens, Greece; \\ ${ }^{8}$ ENT Department, Medical School, University of Patras, Patras, Greece
}

\begin{abstract}
Background/Aim: Oncogene up-regulation combined with suppressor gene down-regulation is a crucial genetic combination that promotes cell neoplastic phenotype and progressively malignant transformation in solid malignancies, including laryngeal squamous cell carcinoma (LSCC). Among oncogenes, the Kirsten ras oncogene homolog (K-Ras) is involved in LSCC onset and progression. Patients and Methods: Sixty $(n=60)$ primary LSCC tissue sections were analyzed by immunohistochemistry (IHC). Digital image analysis (DIA) was also implemented for measuring K-Ras protein expression levels. Results: High KRas protein expression levels were observed in 20/60 (33.3\%) LSCC tissue sections, whereas the rest of the cases $(n=40 ; 66.7 \%)$ demonstrated low expression. Overall K-Ras expression was borderline significantly associated to the grade of the examined malignancies $(p=0.048)$, whereas no other strong statistical correlations were identified. A progressive $K$-Ras overexpression was observed in all grades of the examined cases. Conclusion: K-Ras over expression is correlated to a progressive dedifferentiation in LSCC.
\end{abstract}

This article is freely accessible online.

Correspondence to: Evangelos Tsiambas, Cytopathologist, MD, MSc, Ph.D., Lecturer elect in Molecular Cytology, Medical School, University of Athens 17 Patriarchou Grigoriou E' Street, Ag. Paraskevi, 15341 Athens, Greece. E-mail: tsiambasecyto@yahoo.gr

Key Words: Carcinoma, larynx, oncogene, K-Ras.
Extensive molecular analyses in solid malignancies have identified a broad spectrum of gene functional and numerical imbalances that deregulate critical pathways including signal transduction, apoptosis, cell-cycle progression and angiogenesis (1). In fact, epithelial neoplastic and malignant transformations are promoted by abnormal gene expression combined with oncogene up-regulation and suppressor gene down-regulation (2). A variety of gene modifications including point mutations, polymorphisms, abnormal gene copy number (amplification, deletion), or structural chromosomal rearrangements (translocations) and also epigenetic alterations detectable by different molecular techniques provide critical information for the molecular landscape in solid malignancies (3). Among oncogenes, the Kirsten ras oncogene homolog (K-Ras, Cytogenetic Location: 12p12.1) represents the most important in the corresponding family of genes (proto-oncogenes) that also include $\mathrm{H}$-Ras and $\mathrm{N}$-Ras. These genes encode proteins acting as hydrolase enzymes, converting guanosine triphosphate (GTPase) to GDP. Interestingly, after completing its role in this modification, K-ras is deactivated (4). Among their functions, they promote cell division, cell differentiation, and also, indirectly, programmed cell death (apoptosis), whereas an intrinsic GTPase activity leading to enzyme catalysis has been also confirmed (5). Concerning the involvement of K-Ras in signal transduction, the gene is a member of the RAS/RAF-MEK-ERK/MAPK pathway and indirectly interacts with the PI3K-AKT-PTEN-mTOR pathway (6). Deregulation of K-Ras is detected frequently in solid malignancies as a result of point mutations or amplification (7-11). In the current study, we analyzed K-Ras protein expression levels in LSCCs tissue sections 
in vivo $35: 1611-1615(2021)$

Table I. Clinicopathological parameters and total K-Ras expression results (Pearson Chi square test- $\chi^{2}$ ).

\begin{tabular}{|c|c|c|c|c|}
\hline \multirow{2}{*}{$\begin{array}{l}\text { Clinicopathological } \\
\text { parameters }\end{array}$} & & \multicolumn{2}{|c|}{ K-Ras } & \multirow[t]{2}{*}{$p$-Value } \\
\hline & & $\mathrm{OE}$ & LE & \\
\hline LSCC & $(\mathrm{n}=60)$ & $20 / 60(33.3 \%)$ & $40 / 50(66.7 \%)$ & \\
\hline Gender & & & & 0.309 \\
\hline Male & $58(96.7 \%)$ & $20 / 60(33 \%)$ & $38 / 60(63.3 \%)$ & \\
\hline Female & $2(3.3 \%)$ & $0 / 60(0 \%)$ & $2 / 60(3.3 \%)$ & \\
\hline Anatomical region & & & & 0.704 \\
\hline Supraglotis & $6(10 \%)$ & $2 / 60(3.3 \%)$ & $4 / 60(6.6 \%)$ & \\
\hline Transglotis & $54(90 \%)$ & $18 / 60(30 \%)$ & $36 / 50(60 \%)$ & \\
\hline Grade & & & & 0.048 \\
\hline 1 & $4(6.7 \%)$ & $2 / 60(3.3 \%)$ & $2 / 60(3.3 \%)$ & \\
\hline 2 & $21(35 \%)$ & $4 / 60(6.6 \%)$ & $17 / 60(28.3 \%)$ & \\
\hline 3 & $35(58.3 \%)$ & $14 / 60(23.3 \%)$ & $21 / 60(35 \%)$ & \\
\hline Stage & & & & 0.271 \\
\hline p T3 & $27(45 \%)$ & $7 / 60(11.6 \%)$ & $20 / 60(33.3 \%)$ & \\
\hline p T4 & $33(55 \%)$ & $13 / 60(21.6 \%)$ & $20 / 60(33.3 \%)$ & \\
\hline Alcohol consumption & & & & 0.443 \\
\hline Yes & $51(85 \%)$ & $16 / 60(26.6 \%)$ & $35 / 60(58.3 \%)$ & \\
\hline No & $9(15 \%)$ & $4 / 60(6.6 \%)$ & $5 / 60(8.3 \%)$ & \\
\hline \multicolumn{5}{|l|}{ Treatment regimens } \\
\hline Chemotherapy (C) & $19(31.6 \%)$ & $5 / 60(3.3 \%)$ & $14 / 60(23.3 \%)$ & 0.828 \\
\hline Radiotherapy (R) & $6(10 \%)$ & $3 / 60(5 \%)$ & $3 / 60(5 \%)$ & \\
\hline Combined RT (CRT) & $35(58.3 \%)$ & $12 / 60(20 \%)$ & $23 / 60(38.3 \%)$ & \\
\hline \multicolumn{5}{|l|}{ Tumour size (max diam) } \\
\hline$<3 \mathrm{~cm}$ & $38(63.3 \%)$ & $11 / 60(18.3 \%)$ & $27 / 60(45 \%)$ & 0.272 \\
\hline$>3 \mathrm{~cm}$ & $22(36.6 \%)$ & $9 / 50(15 \%)$ & $13 / 60(21.6 \%)$ & \\
\hline
\end{tabular}

LSCC: Laryngeal squamous cell carcinomas; OE: Over-expression (Moderate to high expression): staining intensity values $\leq 131$ at $100 \%$ of the examined malignant cells (spectrum between 82 and 131); LE: Low expression: staining intensity values $>142$ at $100 \%$ of the examined malignant cells (spectrum between 142 and 179). Statistically significant $p$-Values are shown in bold.

correlating their digitized staining intensity levels with the corresponding clinical-histological features.

\section{Patients and Methods}

Patients and tissue samples. For the purposes of our study, sixty $(\mathrm{n}=60)$ archival, formalin-fixed and paraffin-embedded tissue specimens of surgically resected, histologically confirmed primary LSCCs were used. The specimens were from fifty-eight $(n=58)$ male and two $(n=2)$ female patients, all smokers without a positive DNA test or a clear history of Human Papilloma Virus (HPV) infection. The hospital Ethics Committee consented to the use of these tissues in the Hippocration Hospital, University of Athens, Athens, Greece, for research purposes (Research Protocol Reference ID: 2226/09.09.2018), according to the World Medical Association Declaration of Helsinki guidelines (2008, revised 2014). The tissue samples were fixed in $10 \%$ neutral-buffered formalin. Hematoxylin eosin(H\&E)-stained slides were reviewed for confirmation of the histopathological diagnoses. All lesions were classified according to the histological typing and staging criteria of the World Health Organization (WHO) Pathology Series (12). Clinicopathological data of the examined cases are demonstrated in Table I.
Antibodies and immunohistochemistry assay (IHC). Mouse Monoclonal anti-K-Ras antibody (clone 234-4.2 IgG2a, Abcam, Cambridge, UK; dilution/concentration of 1:100) was selected and applied. IHC for the marker expression was carried out in $4-\mu \mathrm{m}$ serial sections of the corresponding tissue blocks. The corresponding slides were deparaffinised and rehydrated. After rinsing in water, endogenous peroxidase activity was blocked by immersion in 3\% hydrogen peroxide for 5 minutes. The EnVisionTM $^{+}$(Dako, Denmark) detection system was used for the following detection steps. Blocking solution was applied to the slides for $10 \mathrm{~min}$, followed by incubation for $1 \mathrm{~h}$ at room temperature. Following incubation with the secondary antibody for 10 min, diaminobenzidine-tetrahydrocloride-DAB $\quad(0.03 \%)$ containing $0.1 \%$ hydrogen peroxide was applied as a chromogen and incubated for $5 \mathrm{~min}$. Sections were counterstained, dehydrated and cover slips were added. For negative control slides, the primary antibody was omitted. The IHC protocol was performed by the use of an automated staining system (I 6000, Biogenex, San Ramon, CA, USA). Membranous and diffuse cytoplasmic cellular staining patterns were considered acceptable for K-Ras essential expression (Figure 1a and b). Microscopically normal archival colon carcinoma and normal appearing laryngeal epithelia tissue sections expressing $\mathrm{K}$-Ras protein were considered controls for different K-Ras expression patterns. Protein expression levels were evaluated 

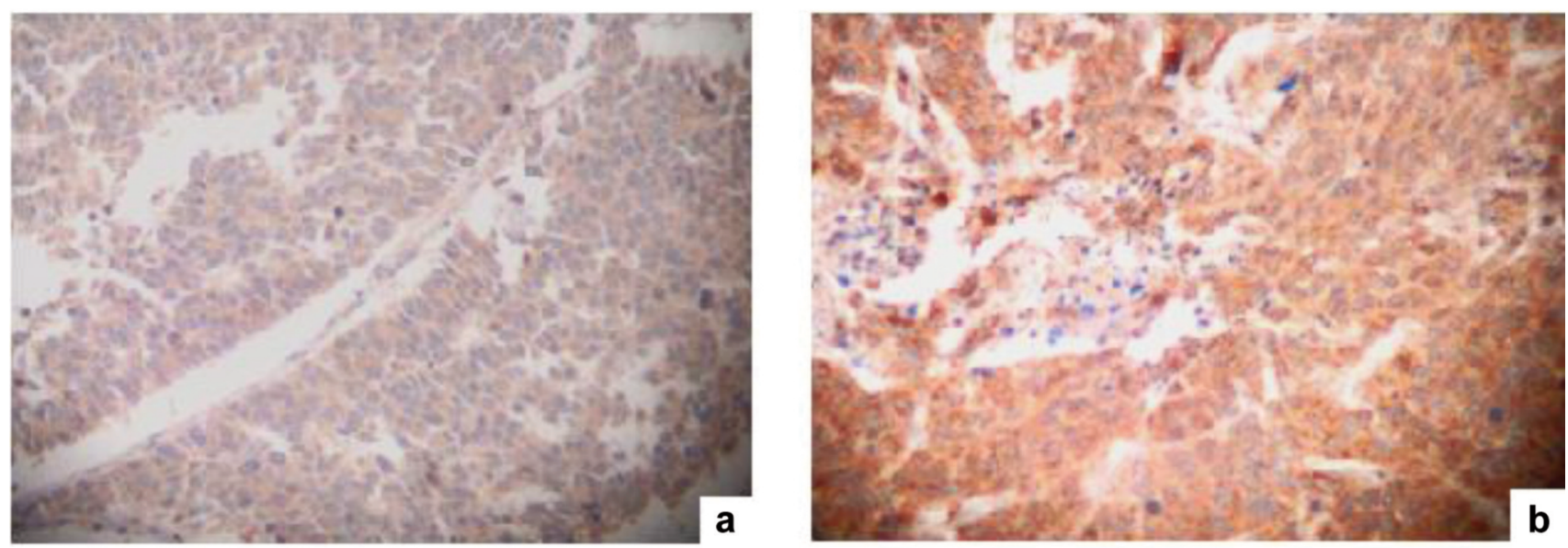

Figure 1. K-Ras protein expression patterns in laryngeal squamous cell carcinoma (LSCC) tissues. (a) Low K-Ras immunostaining level. Note the membranous and diffuse cytoplasmic cellular staining (anti-k-RAS, brown DAB stain), original magnification 100x. (b) High K-Ras immunostaining level.

quantitatively by implementing a digital image analysis protocol. Digital image analysis assay (DIA). K-Ras protein expression levels were evaluated quantitatively by measuring the corresponding staining intensity levels. We performed DIA using a semi-automated system (Microscope: CX-31, Olympus, Melville, NY, USA; Digital camera: Sony, Tokyo, Japan; Windows XP/NIS-Elements Software AR v3.0, Nikon Corp, Tokyo, Japan). Areas of interest per tissue section were identified ( 5 optical fields at $\times 100$ magnification) and filed in a digital database as snapshots. Measurements were performed by implementing a specific macro (diffuse and focal membranous/cytoplasmic protein expression patterns). Based on an algorithm, normal tissue sections (control) were measured independently and compared to the corresponding values in malignant tissue sections. A broad spectrum of continuous grey scale values (0-255) at the RedGreenBlue (RGB) analysis was available for discriminating different protein expression levels. Values decreasing to 0 represent a progressive over-expression of the marker, whereas values increasing to 255 show a progressive loss of its staining intensity. Total results and DIA values are demonstrated in Table I.

Statistical analysis. Descriptive statistics were performed. Associations between variables including protein expression levels and clinicopathological parameters such as gender, tumor grade and stage, anatomic location and alcohol consumption were performed using the Pearson Chi square test $\left(\chi^{2}\right)$ estimated along with its $99 \%$ CI and Spearman Correlation coefficient (SPSS v20; Chicago, IL, USA). Two-tailed $p$-values $\leq 0.05$ were considered statistically significant. Results and correlations ( $p$-Values) are described in Table I.

\section{Results}

All examined tissue sections were evaluated and measured properly by implementing the previously described DIA protocol. High K-Ras protein expression levels were observed in 20/60 (33.3\%) LSCC tissue sections, whereas the rest of the cases $(n=40 ; 66.7 \%)$ demonstrated low expression.
Overall K-Ras expression was borderline significantly associated to the grade of differentiation in the examined malignancies $(p=0.048)$. No other statistically significant associations were identified, correlating protein expression to gender $(p=0.309)$, anatomical region $(p=0.704)$, pT stage $(p=0.271)$, alcohol consumption $(p=0.271)$, treatment regimens $(p=0.828)$ or tumor size $(p=0.272)$.

\section{Discussion}

Alterations in oncogenes and suppressor genes are frequent in LSCCs, but there are controversial results regarding their value as potential independent prognostic biomarkers. A study group co-analyzing p53 and Ras family genes $(\mathrm{K} / \mathrm{H} / \mathrm{N}-$ Ras) in a series of LSCC tissues concluded that a fraction of them demonstrated specific double or triple mutations, but only the p53 and S-phase fraction was found to be a strong biological indicator for predicting the outcome of the examined patients (13). Additionally, another study group reported a low K-Ras mutational incidence -focused on codon 12-point mutations- analyzing LSCC cytological specimens (14). Similarly, a molecular study showed no KRas mutations regarding the codon 12 , whereas sporadic oncogene amplification cases were detected in a series of LSCCs (15).

In the current study, we analyzed K-Ras protein expression by IHC on tissue sections of LSCCS estimating the levels of its staining intensity using a DIA protocol. K-Ras high protein expression levels were observed in a significant proportion of examined tissues. Overall K-Ras expression was associated to the grade of the examined malignancies. A progressive K-Ras over-expression was observed in all grades of the examined cases. Concerning the K-Ras protein over-expression in LSCC, 
another study based on combined IHC and polymerase chain reaction (PCR) reported high levels of protein expression in the examined LSCC tissues, but no evidence of K-Ras codons 12 or 13 point mutations (16). Because this analysis revealed a high K-Ras oncogenic activity not only in carcinomas, but also in dysplasias of different grades, the authors considered its deregulation as an early genetic event potentially triggered by epigenetic changes. Similarly, microRNA (miR) analysis in LSCC based on specific markers such as miR-143-3p seems to add critical molecular information regarding the K-Ras expression patterns in them. A study group suggested that enhanced miR-143-3p inhibited cell growth and metastasis suppressing the K-Ras/Raf/mitogen-activated protein kinase (MEK)/extracellular signal-regulated kinase (ERK) signalling pathway (17). Co-analyzing epidermal growth factor receptor (EGFR) and K-Ras genes by applying high resolution melting analysis (HRMA) and one-step real-time polymerase chain reaction (PCR), a study group reported a very limited K-Ras mutational rate in the Belgian population with Head and Neck Squamous Cell Carcinoma (HNSCC) including LSCC cases (7\% of the specimens, only one case with point mutation) (18). Similarly, another molecular analysis confirmed the absence of K-Ras mutations in codons 12 and 13 of LSCCs, whereas EGFR overexpression was prominent in the corresponding Japanese patients analyzed for the markers by another study (19). In contrast, another study group identified only two cases with a mutant K-Ras at codon 12, whereas EGFR exons 19 and 20 point missense and deletion mutations were detected in significant proportions, whether or not combined with gene amplification (20). Another study group co-analyzing EGFR and KRAS mutations in Greek NSCLC patients detected a low-level mutational status, but KRAS mutations should be considered an independent prognostic factor that negatively affects prognosis in these patients (21). Similarly, another study showed that high co-expression of EGFR and another important molecule (anaplastic lymphoma kinase (-ALK) are associated with an aggressive biological behaviour (advanced stage/grade) in LSCCs (22). Concerning novel micro-genetic markers such as micro-RNAs, a study group showed that a specific variant allele in the KRAS 3' untranslated region involving the let-7 miRNA complementary site (KRASLCS6) is associated with aberrant KRAS expression. Additionally, this variant led to poor prognosis (short survival rates) the corresponding patients (23).

\section{Conclusion}

According to our results extracted by protein analysis implementation in a series of LSCCs, K-Ras over expression is correlated with an aggressive phenotype (advanced grade of dedifferentiation) in LSCCs. Additionally, because K-Ras high expression levels are also observed in a small number of well differentiated carcinomas, its oncogenic activation could be considered an early genetic event in LSCC development, despite its low mutational rates in them. Concerning its clinical significance and impact in LSCC, further molecular analyses should be focused on specific genetic signatures in corresponding patients.

\section{Conflicts of Interest}

The Authors declare no conflicts of interest regarding this study. No financial support was granted.

\section{Authors' Contributions}

ET, EK, V: IHC evaluation, paper writing; DP, NM, DS, VP, AC: patients data collection, paper writing; AN, SM, PP: references data, paper writing.

\section{References}

1 Hanahan D and Weinberg RA: Hallmarks of cancer: The next generation. Cell 144(5): 646-674, 2011. PMID: 21376230. DOI: 10.1016/j.cell.2011.02.013

2 Albertson DG, Collins C, McCormick F and Gray JW: Chromosome aberrations in solid tumors. Nat Genet 34(4): 369376, 2003. PMID: 12923544. DOI: $10.1038 / n g 1215$

3 Sexton RE, Mpilla G, Kim S, Philip PA and Azmi AS: Ras and exosome signaling. Semin Cancer Biol 54: 131-137, 2019. PMID: 30769101. DOI: 10.1016/j.semcancer.2019.02.004

4 Schlessinger J: Cell signaling by receptor tyrosine kinases. Cell 103(2): 211-225, 2000. PMID: 11057895. DOI: 10.1016/s00928674(00)00114-8

5 Moral $\mathrm{M}$ and Paramio JM: Akt pathway as a target for therapeutic intervention in HNSCC. Histol Histopathol 23(10): 1269-1278, 2008. PMID: 18712679. DOI: 10.14670/HH23.1269

6 Sideris M, Emin EI, Abdullah Z, Hanrahan J, Stefatou KM, Sevas V, Emin E, Hollingworth T, Odejinmi F, Papagrigoriadis S, Vimplis $S$ and Willmott F: The role of KRAS in endometrial cancer: A mini-review. Anticancer Res 39(2): 533-539, 2019. PMID: 30711927. DOI: 10.21873/anticanres.13145

7 Van Damme N, Deron P, Van Roy N, Demetter P, Bols A, Van Dorpe J, Baert F, Van Laethem JL, Speleman F, Pauwels P and Peeters M: Epidermal growth factor receptor and K-RAS status in two cohorts of squamous cell carcinomas. BMC Cancer 10: 189, 2010. PMID: 20459770. DOI: 10.1186/1471-2407-10-189

8 Yamashita H, Kotani T, Park JH, Murata Y, Okazawa H, Ohnishi $\mathrm{H}, \mathrm{Ku} \mathrm{Y}$ and Matozaki $\mathrm{T}$ : Role of the protein tyrosine phosphatase Shp2 in homeostasis of the intestinal epithelium. PLoS One 9(3): e92904, 2014. PMID: 24675817. DOI: 10.1371/journal.pone.0092904

9 Yatabe Y, Koga T, Mitsudomi T and Takahashi T: CK20 expression, CDX2 expression, K-ras mutation, and goblet cell morphology in a subset of lung adenocarcinomas. J Pathol 203(2): 645-652, 2004. PMID: 15141379. DOI: 10.1002/ path. 1566

10 S Papanikolaou V, Kyrodimos E, Tsiambas E and Chrysovergis A: K-RAS mutations in laryngeal squamous cell carcinoma. J BUON 24(5): 2207-2208, 2019. PMID: 31786899. 
11 Pochylski T and Kwaśniewska A: Absence of point mutation in codons 12 and 13 of K-RAS oncogene in HPV-associated high grade dysplasia and squamous cell cervical carcinoma. Eur J Obstet Gynecol Reprod Biol 111(1): 68-73, 2003. PMID: 14557015. DOI: 10.1016/s0301-2115(03)00205-7

12 Barnes L: Pathology and genetics: Head and neck tumours. WHO IARC Press, Lyon, France, pp. 118-130, 2005.

13 Russo A, Corsale S, Agnese V, Macaluso M, Cascio S, Bruno L, Surmacz E, Dardanoni G, Valerio MR, Vieni S, Restivo S, Fulfaro F, Tomasino RM, Gebbia N and Bazan V: TP53 mutations and S-phase fraction but not DNA-ploidy are independent prognostic indicators in laryngeal squamous cell carcinoma. J Cell Physiol 206(1): 181-188, 2006. PMID: 15965904. DOI: $10.1002 / j \mathrm{jp} .20447$

14 Rizos E, Sourvinos G, Arvanitis DA, Velegrakis G and Spandidos DA: Low incidence of $\mathrm{H}-, \mathrm{K}$ - and N-ras oncogene mutations in cytological specimens of laryngeal tumours. Oral Oncol 35(6): 561-563, 1999. PMID: 10705090. DOI: 10.1016/s1368-8375(99)00032-9

15 Kiaris H and Spandidos D: Analysis of h-ras, k-ras and N-ras genes for expression, mutation and amplification in laryngeal tumors. Int J Oncol 7(1): 75-80, 1995. PMID: 21552809. DOI: 10.3892/ijo.7.1.75

16 Ruíz-Godoy R LM, Garcia-Cuellar CM, Herrera González NE, Suchil BL, Pérez-Cárdenas E, Sácnchez-Pérez Y, Suárez-Roa ML and Meneses A: Mutational analysis of K-ras and Ras protein expression in larynx squamous cell carcinoma. J Exp Clin Cancer Res 25(1): 73-78, 2006. PMID: 16761621.

17 Zhang F and Cao H: Micro-RNA-143-3p suppresses cell growth and invasion in laryngeal squamous cell carcinoma via targeting the k-Ras/Raf/MEK/ERK signaling pathway. Int J Oncol 54(2): 689-701, 2019. PMID: 30535502. DOI: 10.3892/ijo.2018.4655

18 Boeckx C, Weyn C, Vanden Bempt I, Deschoolmeester V, Wouters A, Specenier P, Van Laer C, Van den Weyngaert D, Kockx M, Vermorken JB, Peeters M, Pauwels P, Lardon F and Baay M: Mutation analysis of genes in the EGFR pathway in head and neck cancer patients: Implications for anti-EGFR treatment response. BMC Res Notes 7: 337, 2014. PMID: 24899223. DOI: 10.1186/1756-0500-7-337
19 Fujii S, Uryu H, Akashi K, Suzuki K, Yamazaki M, Tahara M, Hayashi R and Ochiai A: Clinical significance of KRAS gene mutation and epidermal growth factor receptor expression in Japanese patients with squamous cell carcinoma of the larynx, oropharynx and hypopharynx. Int J Clin Oncol 18(3): 454-463, 2013. PMID: 22441881. DOI: 10.1007/s10147-012-0402-z

20 Szabó B, Nelhubel GA, Kárpáti A, Kenessey I, Jóri B, Székely C, Peták I, Lotz G, Hegedus Z, Hegedus B, Füle T, Döme B, Tímár J and Tóvári J: Clinical significance of genetic alterations and expression of epidermal growth factor receptor (EGFR) in head and neck squamous cell carcinomas. Oral Oncol 47(6): 487-496, 2011. PMID: 21498106. DOI: 10.1016/j.oraloncology. 2011.03.020

21 Linardou H, Kotoula V, Kouvatseas G, Mountzios G, Karavasilis V, Samantas E, Kalogera-Fountzila A, Televantou D, Papadopoulou K, Mavropoulou X, Daskalaki E, Zaramboukas T, Efstratiou I, Lampaki S, Rallis G, Res E, Syrigos KN, Kosmidis PA, Pectasides D and Fountzilas G: Genotyping KRAS and EGFR Mutations in Greek patients with non-small-cell lung cancer: Incidence, significance and implications for treatment. Cancer Genomics Proteomics 16(6): 531-541, 2019. PMID: 31659106. DOI: $10.21873 / \operatorname{cgp} .20155$

22 Politi A, Tsiambas E, Mastronikolis NS, Peschos D, Asproudis I, Kyrodimos E, Armata IE, Chrysovergis A, Asimakopoulos A, Papanikolaou VS, Batistatou A and Ragos V: Combined EGFR/ALK expression analysis in laryngeal squamous cell carcinoma. In Vivo 33(3): 815-819, 2019. PMID: 31028202. DOI: 10.21873 /invivo.11544

23 Christensen BC, Moyer BJ, Avissar M, Ouellet LG, Plaza SL, McClean MD, Marsit CJ and Kelsey KT: A let-7 microRNAbinding site polymorphism in the KRAS 3' UTR is associated with reduced survival in oral cancers. Carcinogenesis 30(6): 1003-1007, 2009. PMID: 19380522. DOI: 10.1093/carcin/ bgp099

Received February 3, 2021

Revised March 6, 2021

Accepted March 8, 2021 